\title{
Castres, Caucalières, Labruguière, Lagarrigue
}

Aérodrome Castres-Mazamet

\section{Chantal Cambon}

\section{(2) OpenEdition \\ 12 Journals}

Édition électronique

URL : http://journals.openedition.org/adlfi/11070

ISSN : 2114-0502

Éditeur

Ministère de la culture

Référence électronique

Chantal Cambon, «Castres, Caucalières, Labruguière, Lagarrigue », ADLFI. Archéologie de la France Informations [En ligne], Midi-Pyrénées, mis en ligne le 01 mars 1997, consulté le 02 mai 2019. URL: http://journals.openedition.org/adlfi/11070

Ce document a été généré automatiquement le 2 mai 2019.

(c) Ministère de la Culture et de la Communication, CNRS 


\title{
Castres, Caucalières, Labruguière, Lagarrigue
}

\author{
Aérodrome Castres-Mazamet
}

Chantal Cambon

Date de l'opération : 1988 (PI)

Inventeur(s) : Cambon Chantal

1 Un vaste secteur situé à l'intersection des quatre communes citées devait faire l'objet d'une extension de l'aérodrome Castres-Mazamet : l'établissement d'une piste de $2200 \mathrm{~m}$, la création de zones de sécurité afférentes, de secteurs de stationnement étaient susceptibles d'amener la réalisation de terrassements considérables, entraînant notamment l'arasement d'une éminence et le comblement de plusieurs combes. Une opération de prospection inventaire a été décidée, avec le concours de l'aménageur, dans tout le secteur que couvre l'emprise du projet.

2 La zone prospectée correspond à un causse calcaire où seules quelques parcelles sont cultivées : les indices de surface les plus nombreux sont des fragments de brique ou de tuile issus des apports de fumure, accompagnés parfois de tessons de céramique vernissée d'époque moderne. La découverte en trois points d'un fragment d'amphore, en quatre points d'éléments en quartz attribuables au Paléolithique inférieur et au Néolithique ont amené la réalisation de sondages complémentaires : ceux-ci ont confirmé la proximité presque immédiate du socle rocheux et le caractère isolé de ces trouvailles.

3 Trois autres sondages ont été réalisés à l'occasion de cette opération : les deux premiers, implantés aux abords de la ferme de Fontcaude, ont intéressé, pour l'un, un mur ruiné attribuable à une clôture et, pour l'autre, les vestiges d'une fontaine située au pied d'une microfalaise : ils ont livré exclusivement des structures attribuables à l'époque moderne.

Le troisième sondage a eu pour objectif de réaliser la coupe d'un chemin (large de 6,60 m), encadré de bordures de pierres et d'un fossé, qui constitue (sur la plus grande partie de son parcours) une limite communale : il a permis de définir la structure de la voie pavée 
de blocs calcaires posés à plat sur un cailloutis, mais n'a pas livré d'éléments permettant d'étayer l'hypothèse d'une datation haute.

INDEX

Index chronologique : Néolithique, Paléolithique, Temps Modernes

Index géographique : Midi-Pyrénées, Tarn (81), Castres, Caucalières, Labruguière, Lagarrigue operation Prospection inventaire (PI) 